\title{
Extra-oral Manifestation of Periapical Periimplantitis
}

\section{Sapundziev¹, D. Dovsak²}

IMPLANT THERAPY OUTCOMES, PERI-IMPLANT BIOLOGY ASPECTS

1. Private Dental Institute Vergina, Ljubljana, Slovenia

2. Dental Surgical Aesthetic D CENTER, Ljubljana, Slovenia

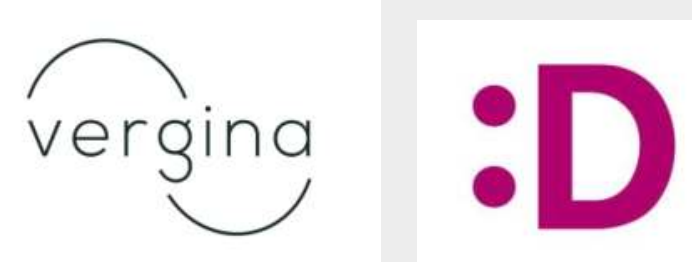

D SURGICAL

\section{Abstract}

Periimplantitis is an inflammatory disease affecting soft and hard tissues around osseointegrated implants. It usually develops after loading and function of implants and is caused by intraoral bacterial flora. It starts from the marginal soft tissue as mucositis and if not treated at this stage spreads into the bone and causes progressive bone resorption and leads to further implant loss.

In rear cases periimplantitis can develop in the periapical region without inflammatory signs in marginal tissues and leads to development of intraoral or extraoral fistulas.

In further presentation we describe a case of periapical periimplantitis (PP) developed 6 months after implant loading presenting with extraoral fistula.

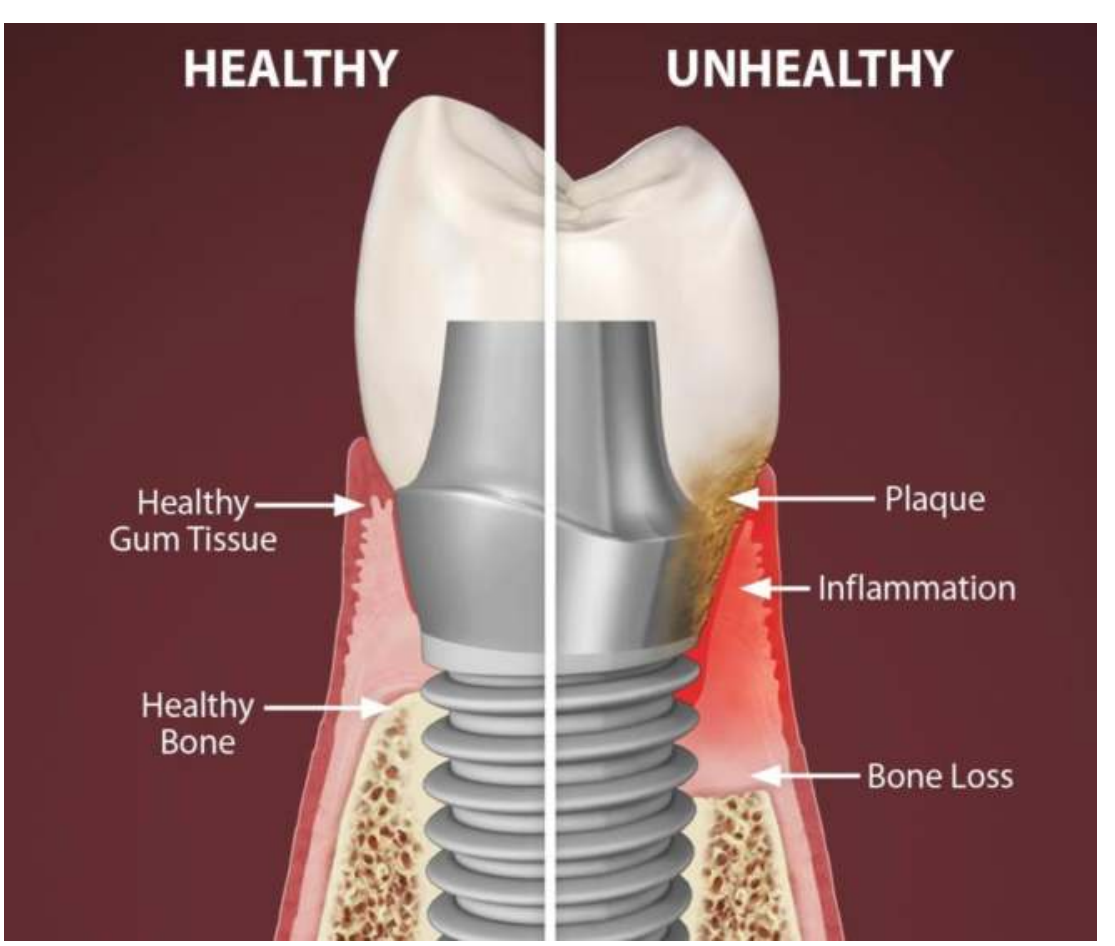

\section{Background and Aim}

Periimplantitis is an infection occurring around an implant caused by microorganisms from intraoral bacterial flora. Its manifestation is usually intraoral and starts as inflammation of marginal soft tissue as mucositis. If untreated, inflammation spreads to marginal bone and affects the bone around implant leading to further bone resorption and implant loss. Sometimes the inflammation can start in the apical part of the implant as periapical periimplantitis (PP) even long time after implant placement.

The aim of this presentation is to present a case report of a patient with PP after implant loading manifesting with development of extraoral fistula.

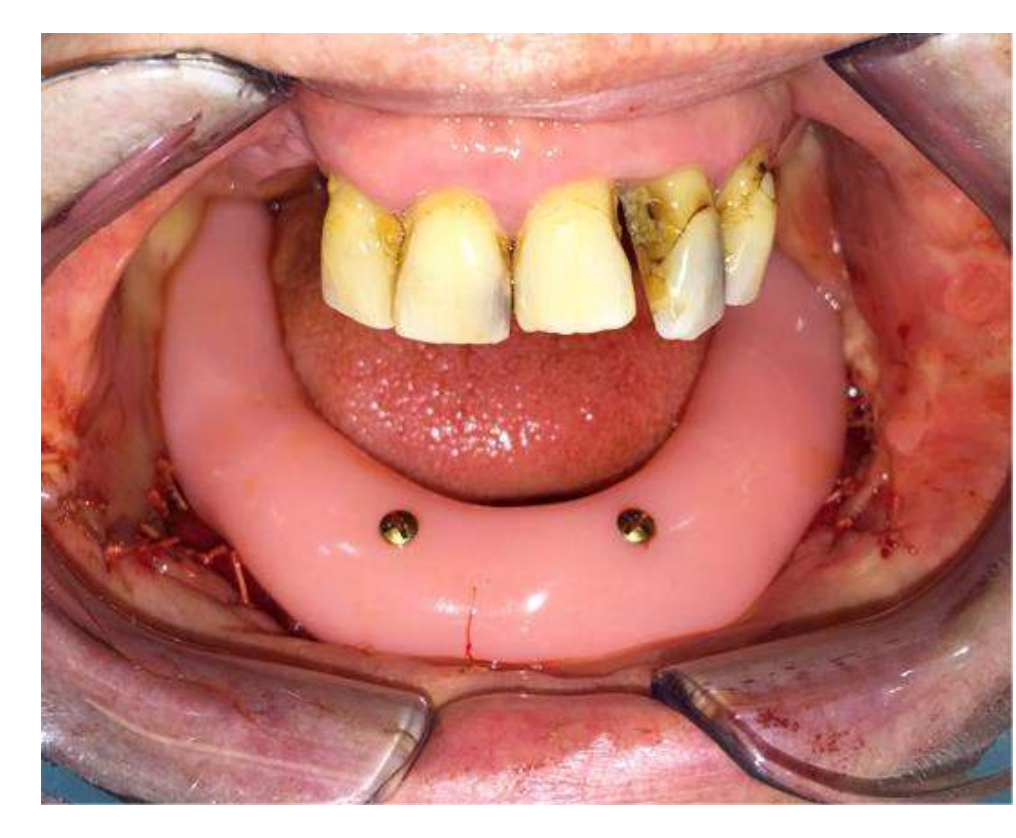

Fig. 1

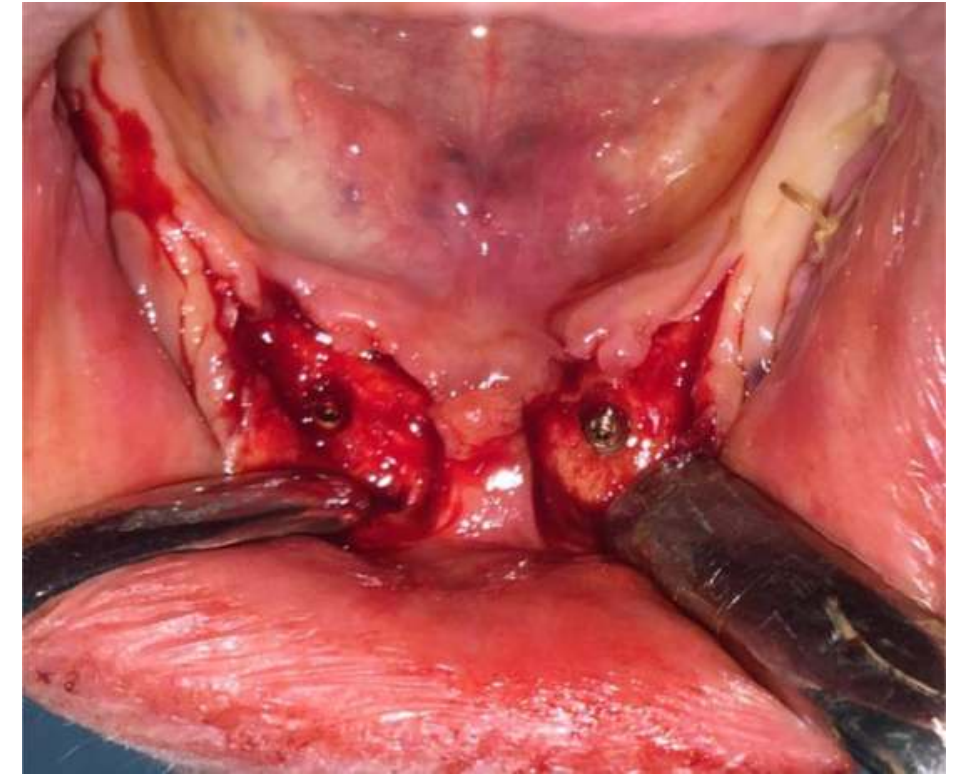

Fig. 2

\section{Methods and Materials}

In healthy female patient who sustained severe car accident two implants were inserted in the interforaminal region for stabilizing lower denture. The implants were inserted after performing vestibuloplasty (Fig.1) due to presence of scars, years after injury and tooth loss. No bone augmentation was performed. Four months after successful osseointegration total prosthesis on locators was administrated (Fig. 2). Six mounts after loading patient presented with extraoral fistula in the chin region on the left side with occasional puss secretion. Standard radiographic evaluation and segmental CB-CT were performed showing presence of chronic inflammation in periapical region of the implant destroying lingual and sub-apical cortex of the mandible (Fig. 3).

Surgical treatment was performed by removing the fistula and inflamed periapical granulated tissue with extraoral approach (Fig. 4).

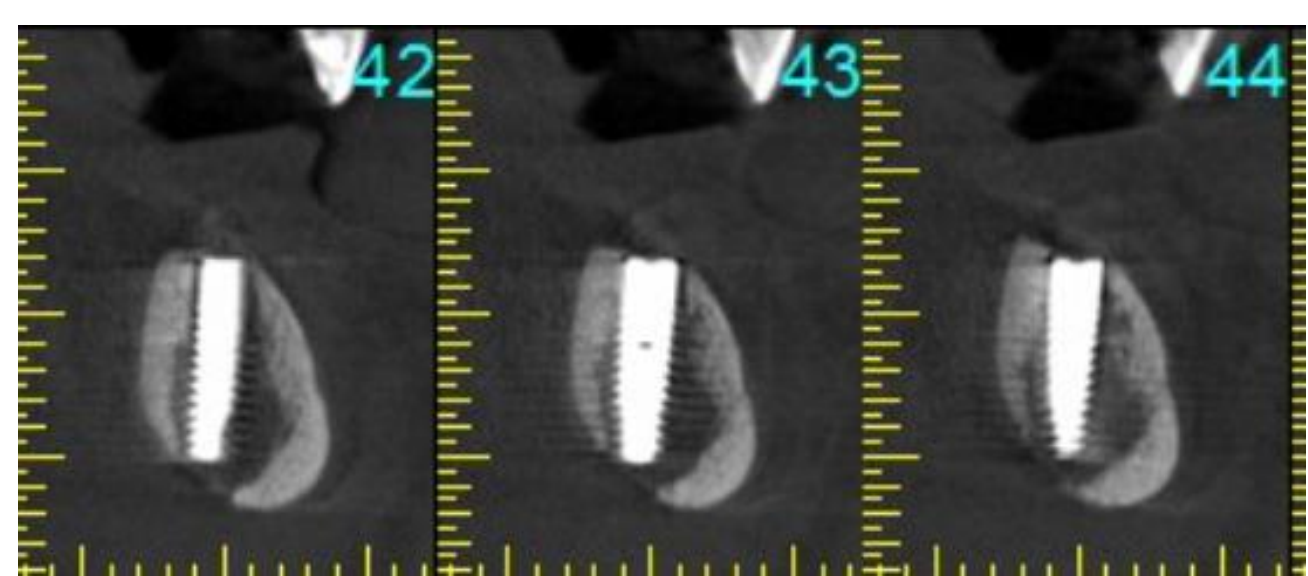

\section{Results}

Complete healing was achieved with good aesthetic outcome one month after the surgical treatment. No implant mobility was observed during and after the healing period. The implants were further loaded without any restrictions (Fig. 5).
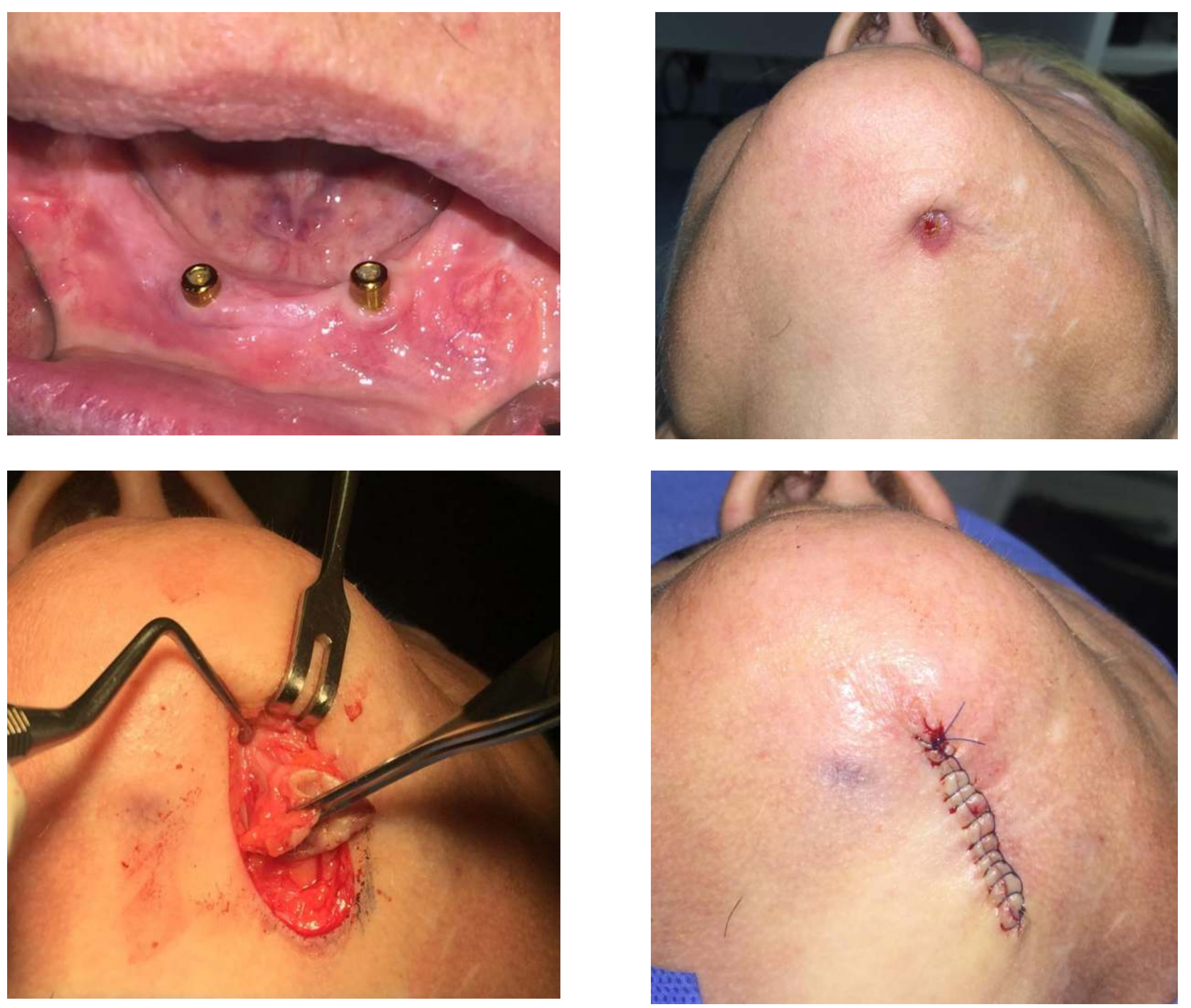

Fig. 4

\section{Conclusions}

Development of PP can be associated with residual infection which in this case was not an issue because teeth were extracted long time before implants were placed and no clinical and radiographic signs for presence of residual inflammation were present. Analyzing this case leaves the opportunity for overheating during drilling in the depth of the bone to be eventual cause for developing of this type of lesions or presence of foreign body reaction.
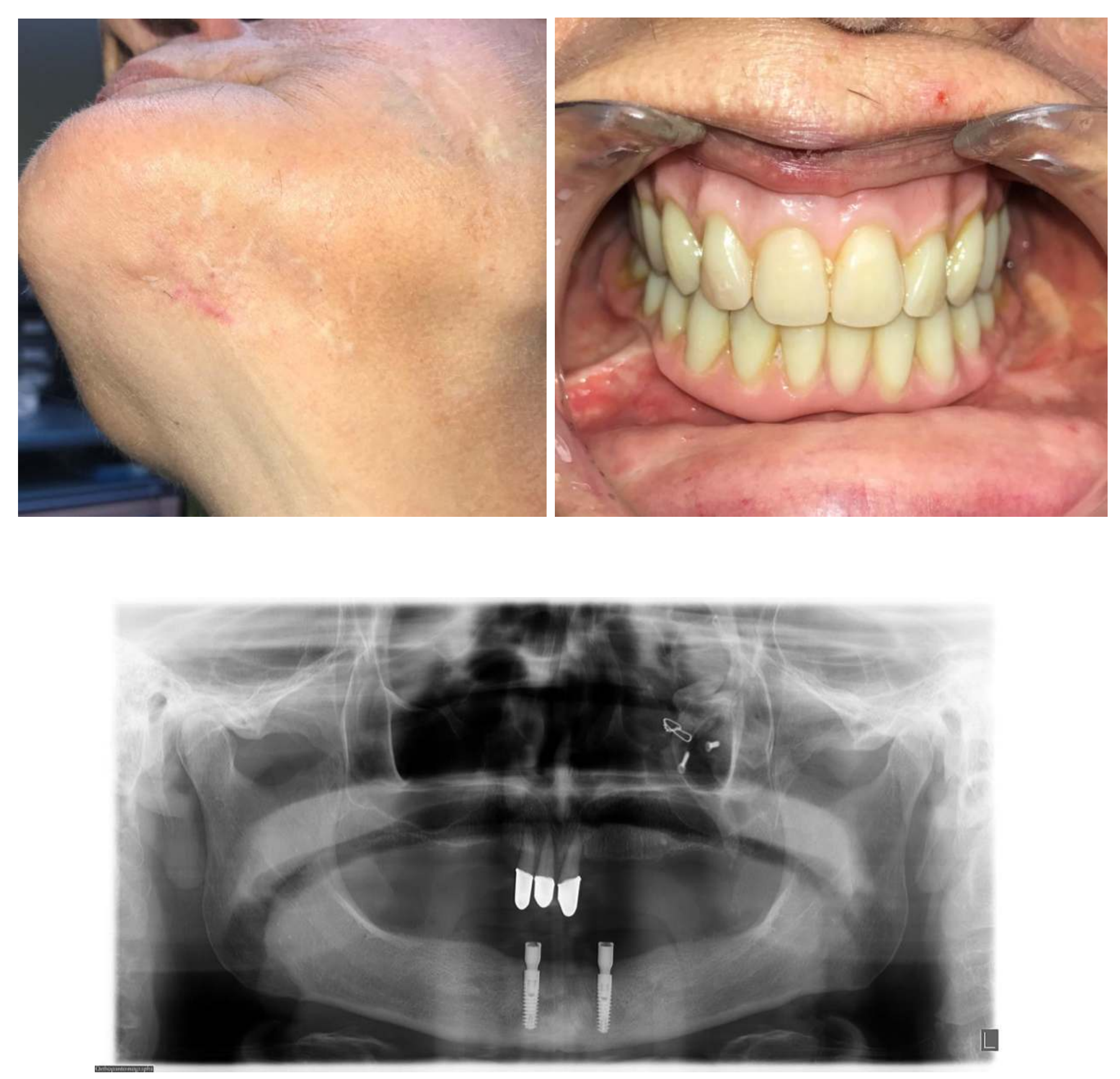

Fig. 5

References

Ramanauskaite A, Juodzbalys G, Tözüm TF. Apical/Retrograde Periimplantitis/Implant Periapical Lesion: Etiology, Risk Factors, and Treatment Bassi F, Poli PP, Rancitelli D, Signorino F, Maiorana C. Surgical Treatment of

3. Temmerman A, Lefever D, Teughels W, Balshi TJ, Balshi SF, Quirynen M. Etiology and treatment of periapical lesions around dental implants.

Quirynen M, Vogels R, Alsaadi G, Naert I, Jacobs R, van Steenberghe D. Predisposing conditions for retrograde peri-implantitits, and treatment
suggestions. Clin Oral Implants Res. 2005 Oct; 16(5):599-608. 